\title{
HEADACHES DURING PREGNANCY IN WOMEN WITH A PRIOR HISTORY OF MENSTRUAL HEADACHES
}

\author{
Eliana Melhado', Jayme A. Maciel Jr², Carlos A.M. Guerreiro ${ }^{3}$
}

\begin{abstract}
Objective: To evaluate the presence of menstrual headaches prior to pregnancy according to the International Headache Society (IHS) classification criteria, 2004, and also study the outcome (fre quency and intensity) of these pre-existing headaches during the gestational trimesters. Method: This study involved 1,101 pregnant women (12 to 45 years old). A semi-structured questionnaire was used to interview the women during the first, second and third gestational trimesters as well as after delivery. All the inteniews were conducted by one of the researchers by applying the IHS Classification (IHSC-2004). Results A 1,029 women out of the 1,101 women interviewed presented headaches prior to gestation, which made it possible to study headaches in 993 women during the gestational trimesters. Menstrually related headaches we represented by 360 of the 993 women. Migraine was re ported by 332/360 women (92.22\%) with menst rual headaches and $516 / 633$ women $(81.51 \%)$ without menstrual headaches, respectively, prior to gestation. The majority of the women with menstrual migraine presented a headache improvement or disappearance during gestation $(62.22 \%$ during the first trimester; $74.17 \%$ during the second trimester; $77.78 \%$ during the third trimester). Conclusion: Most of the pregnant women with menstrual or non-menstrual headaches prior to gestation presented migraine, which either improved or disappeared during pregnancy. Women who suffered from non-menstrual headaches improved during pregnancy but not as much as women with menstrual headaches.
\end{abstract}

KEY WORDS: headache, pregnancy, menstrual, migraine.

\begin{abstract}
Cefaléia durante a gestação em mulheres com história de cefaléia menstrual
RESUMO - Objetivo: Avaliar a presença de cefaléia relacionada ao ciclo menstrual, antes da gestação, classificá-las, segundo os critérios da Sociedade Internacional de Cefaleia (SIC) de 2004, e estudar o comportamento (freqüência e intensidade) dessas cefaléias pré-existentes à gestação durante os trimestres gestacionais. Método: Foram estudados 1101 mulheres grávidas (12 a 45 anos) entrevistadas através de questionário semi-estruturado durante o primeiro, o segundo e o terceiro trimestres gestacionais e imediatamente após o parto. Todas as entrevistas foram conduzidas por um dos autores, usando a classificação da SIC, 2004. Resultados: De 1101 mulheres, 1029 apresentavam cefaléia antes da gestação, sendo possível estudar o com portamento das cefaléias durante os trimestres gestacionais em 993. Apresentaram cefaléia relacionada à menstruação 360/993 mulheres. Encontramos migrânea em, 332/360 (92,22\%) mulheres com cefaléia menstrual e em 516/633 (81,51\%) mulheres com cefaléia não menstrual antes da gestação. A maioria das mulheres com migrânea menstrual apresentou melhora da cefaléia durante a gestação $(62,22 \%$ no primeiro trimestre; $74,17 \%$ no segundo trimestre; $77.78 \%$ no terce iro trimestre). Conclusão: A maioria das mulheres grávidas, com cefaléia tanto menstrual quanto não menstrual, antes da gestação, apresentou migrânea, sendo que a mesma melhora ou desaparece durante a gestação. Mulheres com cefaléia não menstrual antes da gestação melhoram em proporção menor do que aquelas com cefaléia menstrual.
\end{abstract}

PALAVRAS-CHAVE: cefaléia, gravidez, menstrual, migrânea.

The fact that migraine episodes improve during p regnancy in 55 to $90 \%$ of the cases is a common sense ${ }^{1-4}$ and usually occurs in women with non-aura migraines. The menstrually-rdated migraine shows the greatest improvement during pregnancy, especially the strictly menstrual migraine ${ }^{4-9}$.
Migraines that worsen during pregnancy usually do so more often during the first gestational trimester ${ }^{1,2}$. Extensive literature suggests that the cyclic variation of the female sexual hormones is related to migraines ${ }^{10,11}$ and its stabilization during pregnancy ${ }^{11}$ is available.

Deparment of Neurology-State University of Campinas (UNICAMP), Campinas, SP, Brazil and Department of Medicine- Catanduva Medical School, Catanduva, SP, Brazil: ${ }^{1}$ PhD Student, Department of Neurology, State University of Campinas (UNICAMP), Campinas, SP, Brazil; Department of Medicine - Catanduva Medical School, Catanduva, SP, Brazil; ${ }^{2}$ Associate Professor, Department of Neurology, UNICAMP; ${ }^{3}$ Full Professor, Department of Neurology, UNICAMP.

Received 23 March 2005, received in final form 31 May 2005. Accepted 11 July 2005.

Carlos A.M. Guerreiro, MD - Department Neurology / FCM-UNICAMP / PO Box 6111 - 13083-970 Campinas SP - Brazil. E-mail: guerreiro@fcm.unicamp.br 
The purpose of this present epidemiological study was to conduct a follow up of the pregnant women at the prenatal care services in Catanduva (a city with 100,000 inhabitants, northwest of the State of São Paulo, Brazil), in order to classify headaches before gestation according to the 2004 criteria of the International Headache Society (IHS) ${ }^{12}$ and assess the pre-existing menstrually-related and non-related headaches comparing the outcome during the gestational trimesters.

\section{METHOD}

This is a prospective study conducted from January/1998 to June/2002. Patients were interviewed at three public prenatal care services: 1. Hospital Emílio Carlos Outpatient Obstetric Clinic, 2. Hospital Padre Albino Prenatal C a re Inpatient Service, and, 3. Prenatal Care Outpatient Health Center (Centro de Saúde José Perri) in Catanduva, State of São Paulo, Brazil. The three prenatal care services are integrated and all labors are referred to Hospital Padre Albino, a University Hospital. These prenatal care services receive patients from the Catanduva region.

The criteria for inclusion were: 1 . To be pregnant, to ag ree to participate in the study; 2 . To be up to 16 weeks of gestation at the first interview; 3 . The last interview had to be between 36 and 42 gestational weeks or postdelivery (32 weeks in case of twin pregnancy) 4 . To sign the informed consent submitted and approved by the Research Ethics Committee of the institution.

Exclusion criteria were: 1 . Miss the trimester followup visit; 2 . Change in address (city or state) during the research period; 3. Dubious or incongruent information at diffe rent interviews; 4 . Fetal miscarriage or death before the third trimester (resulting in the potential loss of follow up regarding the main objective of the study). Neither previous history of headache nor other medical conditions were considered as exclusion criteria.

The pregnant women underwent an interview according to a semi-structured questionnaire with questions about previous and ongoing pregnancy headaches and gestational conditions. The questionnaire investigated: patient identification- name, age, schooling, occupation, origin, marital status, gestational age; information related to gestation- number of previous gestations, number of prior deliveries, number of prior miscarriages, number of prior Caesarean sections, gestation age (in weeks); smoking; blood pressure; pulse. Several open questions were included: - Have you ever had headache? When was the last time? How many times have you had headache? How long have you had headaches? What are the pain characteristics and location? Do you have photophobia? Phonophobia? Nausea? Vomiting? Osmophobia? Do your symptoms precede or accompany the headache? Premonitory phenomena? Do you have to slow down or interrupt daily activities during the headache? Does the pain get worse during routine physi- cal activity? What is the pain frequency and duration? Is there relationship between your pain and menses? Does it happen before, after or during the menstrual period? How many days before, during or after does it occur? Does it bother your sleep? Does sleep improve the pain? When exactly does the headache start? Do you have aura? If so, how is the aura? During gestation: Have you had headaches during this gestation? Did your headache appear only during this gestation? If you have had headaches before this gestation, how does the pattern now compare regarding intensity and periodicity.

All interviews were conducted by the same author, a neurologist with expertise in headache. First interview was conducted during the first trimester (maximum 16 gestational weeks). Subsequently, follow up visits were established in the second and third trimesters or first days after delivery. After the first interview, patients we reevaluated on two other occasions as outpatients, through home visits, or if otherwise unfeasible, by telephone calls. The aim of these contacts was to assure the pregnancy and headache outcome.

Headaches were classified according to the diagnostic criteria of the IHS (IHSC - 2004) ${ }^{12}$.

Statistical analysis was performed using Chi-square or Fisher's exact test to assess association of the variables of interest. Level of significance was set at $p \leq 0.05$. To assess "pain disappearance + pain improvement" during each gestational trimester, the test and confidence intenal for one proportion was utilized. McNemar (tabulated statistics) test was used to verify headache improvement, deterioration and absence of change between the first and second trimester and between the second and third trimester.

Pain disappearance was considered when patient referred no pain during gestation. Pain improvement was considered when patient referred improvement in at least $50 \%$ frequency or intensity or both.

Menstrual migraine was considered when it occurred two days before and three days after the menstrual flow $^{13,14}$. When it occurred in other part of the period it was called menstrually related migraine. When it occurred exclusively in the menstrual period it was called pure menstrual migraine ${ }^{12}$.

Dependence analysis was performed to compare proportions of women with menstrual and non-menstrual headache.

\section{RESULTS}

One thousand four-hundred and ninety-four pregnant women with headache were interviewed at least once. We excluded 393 patients because of abortions, fetal death before the third trimester, unreliable information or change of address during the gestational period. We interviewed 1,101 women at follow-up consultations during gestation and delivery. Seventy-four women were con- 
Table 1. Headache classification of menstrual related headaches in 360 women, according to the criteria of the IHS -2004.

\begin{tabular}{lcc}
\hline & $\mathrm{N}$ & $\%$ \\
\hline 1.1 Migraine without aura & 140 & 38.89 \\
1.6.1 Probable migraine without aura & 125 & 34.72 \\
1.2 Migraine with aura & 36 & 10.00 \\
2 Tension-type headache & 22 & 6.11 \\
1.1 and 1.2 Migraine without aura and with aura & 20 & 5.56 \\
1.6.2. Probable migraine with aura & 9 & 2.50 \\
8.4.3 Oestrogen-withdrawal headache & 2 & 0.56 \\
8.2 Medication-overuse headache & 2 & 0.56 \\
2.4 Probable tension-type headache & 2 & 0.56 \\
1.5 1 Chronic migraine & 1 & 0.28 \\
1.2.6 Basilar-type migraine & 1 & 0.28 \\
& 360 & \\
\hline
\end{tabular}

$\mathrm{N}$, total of patients.

Table 2. Headache classification of non-menstrual related headaches in 633 women, according to the criteria of the IHS - 2004.

\begin{tabular}{lcc}
\hline & $\mathrm{N}$ & $\%$ \\
\hline 1.6.1 Probable migraine without aura & 219 & 34.60 \\
1.1 Migraine without aura & 197 & 31.12 \\
2 Tension-type headache & 79 & 12.48 \\
1.2 Migraine with aura & 51 & 8.06 \\
1.1 and 1.2 Migraine without aura and with aura & 29 & 4.58 \\
1.6.2 Probable migraine with aura & 13 & 2.05 \\
4.1 Primary stabbing headache & 8 & 1.26 \\
2.4 Probable tension-type headache & 9 & 1.42 \\
8.4.3 Oestrogen-withdrawal headache & 7 & 1.11 \\
1.5 1 Chronic migraine & 6 & 0.95 \\
8.2 Medication-overuse headache & 6 & 0.95 \\
13.11 Cold-stimulus headache & 5 & 0.79 \\
11.3.2 Refraction error headache & 1 & 0.16 \\
1.2.6 Basilar-type migraine & 1 & 0.16 \\
2.3 Chronic tension-type headache & 1 & 0.16 \\
4.8 New daily-persistent headache & 1 & 0.16 \\
Total & 633 & \\
\hline
\end{tabular}

$\mathrm{N}$, total of patients.

tacted by phone calls during second and third trimester or post-delivery.

Age range: 59 (5.3\%) women were between 12 and 15 years, 305 women (27.7\%) between 16 and 19 years, 610 women (55.4\%) between 20 and 30 years and 127 women (11.5\%) were 31 years or older. Average age was 22.95 years.

Educational level [according to Brazilian Law $\mathrm{n}^{\circ} 5692-1971$ and 9394- 1993 ${ }^{15,16}$ ]: 31 (2.8\%) were iIliterate, $715(64.94 \%)$ had less than four years of schooling, $110(10 \%)$ had four years, $108(9.8 \%)$ had less than eight years, $98(8.9 \%)$ had eight years, $18(1.63 \%)$ had more than 8 and less than 11 years and $21(1.9 \%)$ had 11 or more years.

Number of gestations: 457 (41.51\%) women were in first gestation, 304 (27.61\%) were in second, $200(18.17 \%)$ were on third, $87(7.90 \%)$ were in fourth, $30(2.72 \%)$ were on fifth, $14(1.27 \%)$ we re in sixth and $9(0.82 \%)$ were between the seventh and tenth gestations.

Headaches prior to pregnancy were presented by $1029 / 1101$ women $(93.46 \%)$. It was possible to study headache behavior during the gestational trimesters in 993/1029 women.

The following observations were made with re$\mathrm{g}$ ard to the presence of menstru a Il y-related headache in 993 pregnant women who had headaches prior to pregnancy: menstrually-related headache: 360/993 (36.25\%) pregnant women; pure menstrual headache: $19 / 360$ (5.28\%) pregnant women; non-menstrual headache: $612 / 993(61.63 \%)$ pre gnant women; unable to answer: $21 / 993(2.12 \%)$ pregnant women.

The periods during which the headaches oc- 
Table 3. Comparison of headache improvement, deterioration and unchanged condition in the two groups of women with menstrual related and non menstrual related headaches.

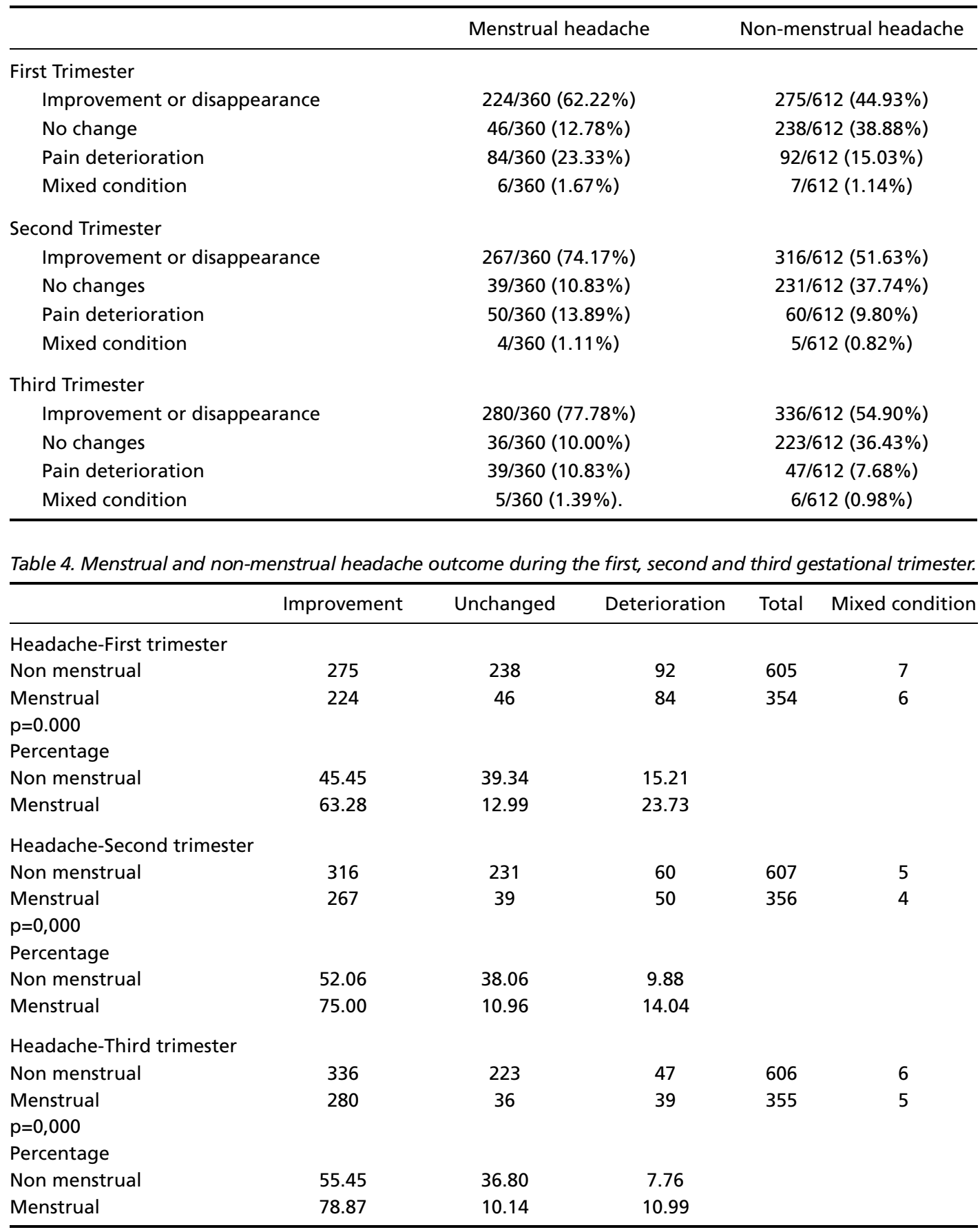

curred in the 360 pregnant women who had menstruation related headaches prior to pregnancy were: headache before menstruation: 198/360 (55.0\%); headache during menstruation: $84 / 360$ (23.33\%); headache before and during menstruation: $27 / 360(7.5 \%)$; headache before and after menstruation: $20 / 360(5.56 \%)$; headache after menstruation: $13 / 360$ (3.61\%); headache before, during and after menstruation: 11/360 (3.06\%); unable to report the period during which the headaches occurred: $7 / 360(1.94 \%)$.

Table 1 shows the classification of menstrualIy-related headaches suffe red by 360 women before pregnancy according to the diagnostic criteria of the HIS-2004 ${ }^{12}$.

Table 2 shows the classification of headaches, according to the criteria of the IHS in 633 pregnant women who had headaches prior to preg- 


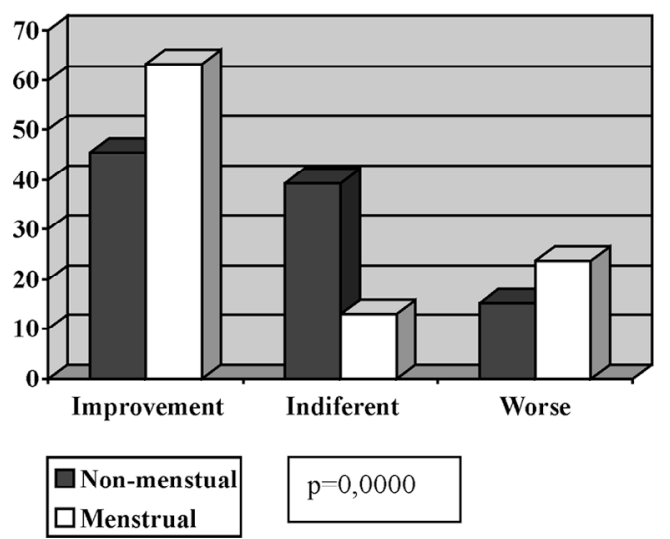

Fig 1. Menstrual and non-menstrual headache outcome dur ing the first trimester.

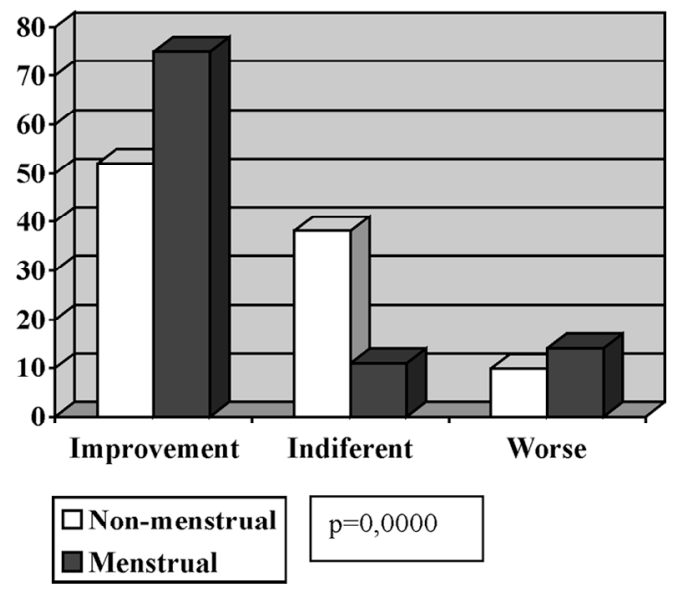

Fig 2. Menstrual and non-menstrual headache outcome dur ing the second trimester.

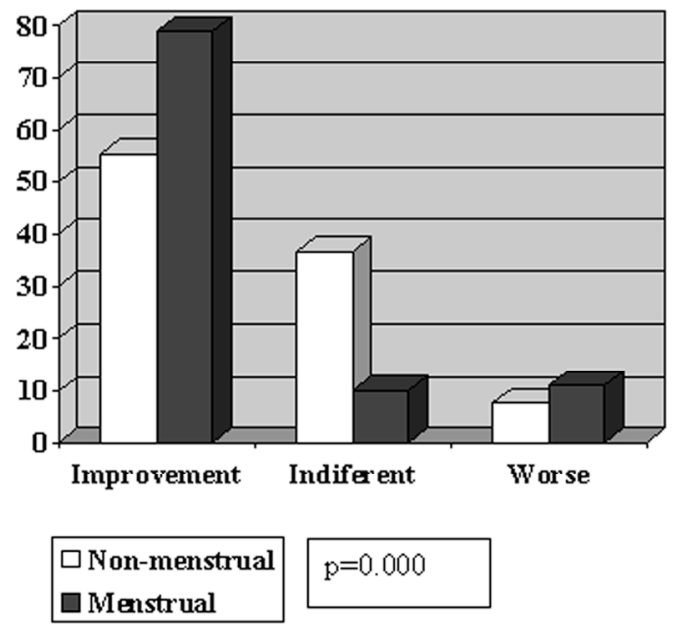

Fig 3. Menstrual and non-menstrual headache outcome dur ing the third trimester. nancy, non-related to the menstrual cycle as well as those who did not know if their headaches were related to the menstrual cycle (21/633).

The headache pattern before pregnancy in 360/993 pregnant women with menstrually-re lated headaches during the gestational trimesters re$\mathrm{g}$ a rding improvement and disappearance, deterioration or unmodified pain is shown according to the gestational trimester.

First trimester - Improvement + disappearance: $224 / 360(62.22 \%)$ pregnant women; unmodified pain: $46 / 360$ (12.78\%); increased pain: $84 / 360$ (23.33\%); mixed condition: 6/360 (1.67\%) (less frequent with more intensity and vice-versa).

Second trimester - Improvement + disappearance: $267 / 360$ (74.17\%); unmodified pain: $39 / 360$ (10.83\%); increased pain: 50/360 (13.89\%); mixed condition: $4 / 360$ (1.11\%). Tabulated statistics: the evidence revealed that the improvement in the second trimester was greater than in the first $(p=0.0000)$.

Third trimester - Improvement + disappearance: 280/360 (77.78\%) women; unmodified pain: $36 / 360$ (10.00\%) women; increased pain: 39/360 (10.83\%) women; mixed condition: 5/360 (1.39\%). Tabulated statistics: the evidence revealed that the improvement in the third trimester was greater than in the second $(p=0.003)$.

Regarding the pattern of non-menstrual related headaches (612 - as 21 women were not able to specify if they were menstrual or non-menstrual related), the results were the following:

First trimester - Improvement + disappearance: 275/612 (44.93\%) women: unmodified pain: 238/612 (38.89\%) women; increased pain: $92 / 612$ (15.03\%); mixed condition: $7 / 612(1.14 \%)$.

Second trimester - Improvement + disappearance: $316 / 612$ (51.63\%) women; unmodified pain: 231/612 (37.75\%) women; increased pain: 60/612 (9.80\%) women; mixed condition: $5 / 612(0.82 \%)$. Tabulated statistics: there is evidence that greater improvement occurred in the second trimester than in the first $(p=0.0000)$.

Third trimester - Improvement + disappearance: 336/612 (54.90\%) women; unmodified pain: 223/ $612(36.44 \%)$ women; increased pain: $47 / 612$ (7. $68 \%$ ) women; mixed conditions: 6/612 (0.98\%). Tabulated statistics: there is evidence that the im- 
p rovement was greater in the third trimester than in the second $(p=0.0002)$.

Table 3 compares the improvement percentage, deterioration and non-modification of headaches in two groups of women with menstrual and non-menstrual headaches. There is evidence of an association between the outcome pattern of headaches in the first and second gestational trimesters; and between second and third trimesters: although the change in the outcome pattern of both menstrual and non-menstrual headaches in the first and second trimester, and second and third trimester is small $(p=0.000$ and $p=0,000$ respectively) is significant.

The pattern of menstrual and non-menstrual headaches during the trimesters revealed a significant difference in each trimester using the dependent analysis method (Table 4 and Figs 1, 2, 3). Women with menstru ally-related headache demonstrated a greater improvement and disappearance of headaches than the women with non-menstrual headaches.

Menstrually-related headaches occurred in $188 / 360(52.22 \%)$ pregnant women since menarche; $16 / 360(4.45 \%)$ women who did not know if the headaches were related to menarche; 156/360 (43. $33 \%$ ) denied that menstrually-related headaches occurred since menarche.

There was no evidence of a relationship of menstrually-related headache outcome initiated at menarche or not in the first gestational trimester $(p=0.54)$, in the second gestational trimester $(p=$ $0.42)$ and the third gestational trimester $(p=0.27)$ using the dependence analysis method, which meant that headaches initiated at menarche did not reveal more significant improvement than headaches that did not begin at menarche.

The dependence analysis did not reveal a statistically significant difference in relation to the three trimesters regarding the behavior displayed by different forms of headaches according to the IHSC$2004^{13}$ (tension-type headache, migraine without aura, probable migraine without aura, migraine with aura) in the group of women with menstrually-related headaches (360): first trimester $p=0.28$; second trimester $p=0.39$ and third trimester $p=0.75$ ). This indicates that there is not a type of headache that presents a predominant improvement or deterioration.

\section{DISCUSSION}

This screening study was conducted through personal interviews by a single neurologist specially trained in the diagnosis and treatment of headache, using a semi-struct c red questionnaire that was complemented by open questions as appropriate. This is considered the best procedure for obtaining relevant information for distinguishing the different types of headaches ${ }^{17,18}$. The women included in this study used the public prenatal care assistance in Catanduva, a medium sized Brazilian city. Most of these women had a low education level, less than four school years.

Majority of these pregnant women presented a history of headaches prior to gestation that were classified as migrainous according to the IHS, 2004 13 in a large number of cases.

Majority of the epidemiological studies ${ }^{1-4,6,7,10}$ demonstrate that pregnant women with headaches prior to pregnancy report an improvement in 55 to $90 \%$ of the cases, while in a smaller contingent of pregnant women, there is an onset of headaches during pregnancy ${ }^{5}$.

In this present study, women with menstrually-related headaches presented a greater percentage of improvement and disappearance of the headaches than the non menstrual headache women. However, the improvement in both groups incre ased progressively from the first to the third trimester, exactly as in the international literature ${ }^{19-21}$. Other studies did not detect a relationship between improvement of headaches and menstruallyrelated headaches ${ }^{22}$.

Majority of the epidemiological studies in the literature on headaches and pregnancy were retrospective ${ }^{2,5}$, while this present study accompanied the pregnant women during the three gestational trimesters. Although some of the studies were retrospective and the present study prospective, all confirmed the same headache improvement patte rnduring the three gestational trimesters with a significantly high improvement in the second trimester and even higher improvement in the third trimester.

A recent prospective study revealed that there was an improvement or migraine remission in $46.8 \%$ during the first trimester, $83 \%$ during the second trimester and $87 \%$ in the third gestational trimester $^{24}$, which once again confirmed the findings of this prospective study that demonstrated a pro- 
gressive improvement in the headaches during the trimesters.

Regular occurrence of migraines approximate ly two days before and three days after the menstrual flow are considered menstrual migraine ${ }^{13,14}$. Migraines that occur from seven days up to three days before the menstrual flow may be considered as premenstrual migraine and associated with the premenstrual syndrome ${ }^{24}$. Between 52 to $70 \%$ of the migraine cases in women are related to the menstrual cycle $\mathrm{e}^{10,25-27}$. Migraines that occur exclusively during the menstrual flow are called "true menstrual migraine" (between 24 to 48 hours beforebleeding onset) ${ }^{25}$ and affect approximately $14 \%$ of the migraine individuals ${ }^{10,25-27}$. Our report demonstrates relatively low percentages of menstrually-related headaches and migraines that occur exclusively during menstruation (36\% and $5 \%$, respectively). The above cited definitions for menstrual migraines were applied in this study. Classic population studies ${ }^{5}$ demonstrate that menstruation triggers off migraine in only $24 \%$ and tensional headaches in $39 \%$, results very close to those obtained by this present study.

According to Rasmussen ${ }^{3}$, migraine crises occur a day or two before menstruation in $67 \%$ of the cases and during menstruation in $\mathbf{2 8 \%}$. These results were similar to those obtained in this study, where the occurrence of headaches before menstrual flow is more common (55\%) and during menstrual flow comes second $(23 \%)$.

This present study did not detect a difference in the percentage improvement between menarche related and non related headaches during pregnancies.

The results demonstrate that the majority of p regnant women with headaches presented these symptoms before pregnancy. The most common etiology in both, women with menstrual headaches as well as non-menstrual headaches prior to pregnancy was migraine ${ }^{12}$.

In most of the women, the headaches improved or disappeared during pregnancy, particularly during the last two trimesters. Menstrually-related headaches demonstrated the greatest improvement or disappeared during pregnancy, while menstrual headaches that began at menarche did not present greater improvement than menstrual headaches that did not begin at menarche.
Acknowledgements - We would like to thank all the pregnant women who participated in this study.

\section{REFERENCES}

1. Somerville BW. A study of migraine in pregnancy. Neurology 1972; 22:824-828.

2. Lance JW, Anthony M. Some clinical aspects of migraine. A prospective survey of 500 pacients. Arch Neurol 1966;15:356-361.

3. Rasmussen BK, Breslau N. Epidemilogy. In: Olesen J, Tfelt-Hansen P, Welch KMA, (eds). The headaches. New York: Raven Press, 1993:169-173.

4. Ciciarelli, MC. Cefaléia e ciclo hormonal. In Specialli JG, Silva WF, (eds). Cefaléias. São Paulo: Lemos, 2002:181-200.

5. Granella F, Sances G, Zanferrini C, Costa A, Martignoni E, Manzoni GC. Migraine without aura and reproductive life events: a clinical epidemiological study in 1300 women. Headache 1993;33:385-389.

6. Chein TC, Leviton A. Headache recurrence in pregnant women with migraine. Headache 1994;34:107-110.

7. Hainline B. Headache. Neurol Clin 1994;12:443-460.

8. Aubé M. Migraine in pregnancy. Neurology 1999;53(Suppl 22): S26-S28.

9. Bousser MG. Migraine, female hormones, and stroke. Cephalalgia 1999; 19:75-79.

10. Siberstein SD. Migraine and women. The link between headache and hormones. Posgrad Med 1995;97:147-153.

11. Ukins A, Silberstein SD. Migraine and pregnancy. Headache 1991;31:372-374.

12. Headache Classification Subcommittee of the International Headache Society. The International Classification of Headache Disorders $\left(2^{\text {nd }}\right.$ Edition). Cephalalgia, 2004;24(Suppl1):S1-S151.

13. MacGregor EA. Menstrual migraine: towards a definition. Cephalalgia 1996;16:11-21.

14. MacGregor EA, Chia H, Vohrah RC, Wilkinson M. Migraine and menstruation: a pilot study. Cephalalgia 1990;10:305-310.

15. Brasil. Lei $n^{\circ} 5692$, de 11 de agosto de 1971 . Fixa diretrizes e bases para o ensino de $1^{\circ}$ e $2^{\circ}$ graus, e dá outras providências. Disponível em: http:/ / www.pedagiaemfoco.pro.br/15692_71.htm. Accessed on July 24,2003.

16. Brasil. Lei ${ }^{\circ} 9394$, de 20 de dezembro de 1996. Estabelece as diretrizes e bases da educação nacional. Diário Oficial [da] República Federativa do Brasil, Brasília. DF, 23 dez. 1996. Disponível em: http: / / www.sed uc.mt.gov/marcos_legais / word/LDB.pdf. Accessed on July 24, 2003.

17. Rasmussen BK, Jensen $R$, Olesen J. Questionnaire versus clinical interview in the diagnosis of headache. Headache 1991;31:290-295.

18. Ramussen BK, Stew art WF. Epidemiology of migraine. In Olesen J, Tfelt-Hansen P, Welch, KMA (eds), The headaches, Philadelphia: Lippincott Williams and Wilkins, 2000:227-233.

19. Ratinahirana H, Darbois $Y$, Bousser M-G. Migraine and pregnancy: a prospective study in 703 women after delivery. Neurology 1990;40:437.

20. Epstein MT, Hockaday JM, Hockaday TDR. Migraine and reproductive hormones throughout the menstrual cycle. Lancet 1975;8:543-548.

21. Cupini LM, Matteis M, Troise E, Calabresi P, Bernardi G, Silvestrini M. Sex-hormone-related events in migrainous females: a clinical comparative study between migraine with aura and migraine without aura. Cephalalgia 1995;15:140-144.

22. Ma raus DA, Scharff L, Turk D. Longitudinal prospective study of headache during pregnancy and postpartum. Headache 1999;39:625-632.

23. Sances G, Granella F, Nappi RE, Fignon N, Ghiotto FP, Nappi G. Course of migraine during pregnancy and postpartum: a prospective study. Cephalalgia 2003;23:197-205.

24. Fettes I. Menstrual migraine. Methods of prevention and control. Postgrad Med 1997;101:67-75.

25. Welch KMA. Migraine and ovarian steroid hormones. Cephalalgia 1997;17(Suppl 20):S6-S12

26. Holm JE, Bury L, Suda K. The relationship between stress, headache, and the menstrual cycle in young female migraneurs. Headache 1996, 36:531-537.

27. NatteroG,Allais G, De Lorenzo C, et al. Menstrual migraine: new biochemical and psychological aspects. Headache 1988;28:103-107. 